\title{
La propuesta pedagógica antimaquiavelista de las Empresas políticas de Diego Saavedra Fajardo
}

\author{
Fernando IBARRA CHÁVEZ \\ Universidad Nacional Autónoma de México
}

\begin{abstract}
Con el fin de contrarrestar la influencia negativa de Maquiavelo en España muchos tratadistas se dedicaron a interpretar El príncipe y otras obras filósóficas del autor para hacer evidente su inconveniencia política. Diego Saavedra Fajardo escribió un texto en el que adoptó la emblemática como procedimiento mnemotécnico y pedagógico. En la primera parte de su libro indica cómo debería ser la educación del príncipe desde la infancia para dirigirlo en la búsqueda por preservar la Razón de Estado sin contradecir la moral cristiana y, sobre todo, alejándose del nocivo maquiavelismo. El presente trabajo tiene la intención de analizar algunos consejos pedagógicos que servirían como "antídoto" para evitar que el futuro gobernante pudiera considerar convenientes las enseñanzas de Maquiavelo.
\end{abstract}

PALABRAS ClAVE: antimaquiavelismo, empresas, emblemas, Saavedra Fajardo, pedagogía.

With the purpose of counteracting the negative influence of Maquiavelo in Spain and with the aim of demonstrating his political inconvenience, a lot of writers dedicated their work to interpret The Prince and other philosophical works written by the Italian author. Diego Saavedra Fajardo wrote a text in which he adopted the emblem as a mnemonic and educational procedure. In the first part of his book, he indicates how the prince's education should be in his early years, all in order to direct him into the research of preserving the National Interest without contradicting Christian morals and, above all, by staying away from the injurious Machiavellism. The present article seeks to analyze some of the educational advices that work as an "antidote" for the possibility of the future governor to consider Maquiavelo's teachings adequate.

KEY WORD: Anti-machiavellism, task, emblems, Saavedra Fajardo, teaching.

Durante los siglos XVI y XVII surgió una fuerte corriente de pensadores políticos que se oponían rotundamente al seguimiento de las doctrinas maquiavelistas por considerarlas amorales e, incluso, demoniacas. Curiosamente, suelen atribuirse a Maquiavelo muchas afirmaciones o conceptos — como el de Razón de Estado — que en realidad no le pertenecen, ${ }^{*}$ sino que se difundieron gracias a sus numerosos partidarios, protestantes

* El término "Razón de Estado", aunque en los tratados españoles está estrechamente ligado a las ideas políticas de la época, en realidad no es un concepto acuñado por Maquiavelo, sino más bien la consolidación de una idea a partir de la publicación de Della Ragione di Stato de Giovanni Botero (1589). 
en su mayoría. Rivadeneira, por ejemplo, en los preliminares de su Tratado de la religión y virtudes que deve tener el Príncipe Christiano para governar y conservar sus Estados. Contra lo que Nicolás de Maquiavelo y los Políticos deste tiempo enseñan, considera que Maquiavelo, a través de Lutero y Calvino, fue el satánico autor intelectual del cisma religioso:

Sembró al principio este mal hombre y ministro de Satanás esta perversa y diabólica doctrina en Italia... Después con las herejías que el mismo Satanás ha levantado, se ha ido extendiendo y penetrando a las de Francia, Flandes, Escocia, Inglaterra otras abrasadas con el fuego infernal dellas, y con ser increíbles las calamidades que con este incendio padecen, no son tantas, ni tan grandes, como las que ha causado esta doctrina de Machiavelo (1595: s. p.).

Prueba de la corriente antimaquiavelista es la aprobación de Francisco de Puga y Feijoo a la edición de Príncipe perfecto y ministros ajustados. Documentos políticos y morales en emblemas de Andrés Mendo, donde se indica cómo debería ser un príncipe según los parámetros de la Iglesia de la Contrarreforma:

Su enseñanza es la Idea de un Príncipe Perfecto y siendo éste o alma, o cabeza del cuerpo de la República, bien se deja entender cuán benignas influencias causara su virtud en las costumbres de sus vasallos, y cuánto mejor obraran éstos advertidos de su ejemplo. Con que hallarán en esta obra los Príncipes qué aprender y los vasallos, qué imitar y todos cuánta enseñanza Cristiana y Política conduce, para saber gobernar y obedecer (Mendo, 1662: s. p.).

La meta principal del príncipe es la conservación del Estado; ésta es una certidumbre en la que coinciden tanto los tratadistas maquiavelistas como sus opositores; la diferencia entre ambos bandos, sin embargo, es bastante clara: todo depende de los medios de los que se valga para conseguir tal fin. Así, el príncipe puede en todo momento aspirar a la virtud y emular la ejemplaridad moral de sus homólogos del pasado, respetando siempre las Sagradas Escrituras, o se puede ayudar de cuánto le sea útil para alcanzar sus objetivos, incluso recurriendo a la maldad o a la injusticia. Gonzalo Fernández de la Mora sintetiza de este modo la manera en que se interpretaba el saber político de Maquiavelo en la España del siglo XVII: "El fin del Estado es su propia conservación, no hay nada, pues, nada ni nadie a quien el Estado deba servir, ya que él es fin en sí mismo y, por tanto, último y supremo fin al que todo debe subordinarse" (1949: 432). Siendo el Estado fin en sí mismo, el príncipe sería un siervo que goza de autonomía moral y legal para cumplir con sus funciones políticas. Bajo esta concepción, incluso la religión debería someterse al servicio del Estado. Resumiendo lo que varios pensadores españoles creían que debería ser la verdadera figura del príncipe cristiano, Quintín Aldea describe al soberano ideal como

[...] el hombre que mira siempre al norte de la verdadera religión, poniendo en ella la firmeza y seguridad del Estado y las esperanzas de sus victorias; que, consultando 
con los tiempos pasados, presentes y futuros, enseña a sustentar la Corona con la reputación y a no depender de la opinión vulgar; a mostrar un mismo semblante en ambas fortunas; a sufrir y esperar; a reducir a felicidad las adversidades; a navegar con cualquier viento; a elegir de dos peligros el menor (1986: XXI).

Otros intelectuales de la época que estaban en contacto directo con la política de la corte española y que se dieron cuenta de que la naturaleza del campo religioso y del político no eran indivisibles, idearon propuestas pedagógicas integrales para abordar el maquiavelismo sin anteponer condenas morales, educando al príncipe según la que consideraban "verdadera" Razón de Estado cristiana antes de que se pudiera volver un ser aberrante como el príncipe tirano que parece ser propuesto como modelo ejemplar por Nicolás Maquiavelo. Don Diego Saavedra Fajardo fue uno de ellos.

Saavedra Fajardo responde con tono preceptivo al fundamento descriptivo de Maquiavelo. No pretende hablar de política desde una posición moralista y condenatoria como Rivadeneira, ni de una manera utópica como Juan de Salazar, sino que toma conciencia de la realidad política española de su tiempo para proponer una solución concreta, razonada, inmediata y vanguardista tanto a la verdadera Razón de Estado como a las cualidades cristianas del príncipe. Para Saavedra hablar sobre la educación de un príncipe no es un ejercicio retórico, como el que practicaban varios de sus contemporáneos, sino un acto político comprometido (Fernández, 1986: 113-117).

Según la primera edición de las llamadas Empresas políticas de Diego Saavedra Fajardo (Mónaco: Nicolao Enrico, 1640), el título original de la obra era Idea de un príncipe político cristiano representada en cien empresas. Ya desde este momento surgen algunos cuestionamientos, pues, en primera instancia, no resulta muy claro a qué se pueda referir el autor con el término 'idea' y, sobre todo, no parece del todo coherente el maridaje del término 'político' con 'cristiano'. 'Idea' no alude simplemente a cualquier representación mental; atendiendo su significado etimológico, 'idea' quiere decir aspecto, apariencia, forma o modelo. Según la filosofía platónica, 'idea' es la esencia, la forma arquetípica de las cosas más allá de sus aspectos particulares o accidentales, que sólo puede conocerse mediante una abstracción de tipo meramente intelectual. Según el Diccionario de autoridades, 'idea' es "plan y disposición que se forma en la fantasía para la construcción de algún edificio, casa, iglesia estatua o pintura. Los filósofos la llaman ejemplar interno del artífice". En este sentido, el texto de Saavedra Fajardo no propone un patrón absoluto, concreto y actualizable, sino una construcción mental del modelo del príncipe. 'Político' es otro término problemático porque no todos los tratadistas aplican el término 'política' o 'político' de la misma manera. Para algunos, la 'política' es simplemente un campo de acción cuyas repercusiones pueden apegarse o no a la doctrina cristiana, y no necesariamente debe coincidir con la Razón de Estado. Para otros, estos dos elementos deberían regirse por los mismos principios morales. Por extensión, el 'político' es el hombre que se dedica a la política - entendida como gobierno y administración-, aunque, en la realidad textual, no siempre se puede entender como equivalente a hombre de Estado o a pensador político; 


\section{$18 \square$ LA PROPUESTA PEDAGÓGICA ANTIMAQUIAVELISTA DE LAS EMPRESAS POLÍTICAS}

además, su connotación positiva o negativa depende de su deferencia hacia la moral cristiana ortodoxa. Según explica José Luis Gómez Martínez, Saavedra estaba consciente de la naturaleza del término y lo usó ex profeso como reflejo de sus convicciones morales (1979: 381-383). El príncipe no puede actuar solo, necesita de consejeros que lo ayuden y estimulen a la preservación y engrandecimiento del Estado. Según los tratadistas de la época, los malos consejeros, es decir, los de evidentes tendencias maquiavelistas, eran llamados generalmente 'políticos' y, con frecuencia, criticados, acusados y denunciados por los opositores de Nicolás Maquiavelo. De hecho, Rivadeneira considera que los políticos son prácticamente una secta satánica de las peores que se hayan visto en el mundo, mientras que, para otros pensadores, 'político' es casi sinónimo de 'impío'. Claudio Clemente se refiere a los políticos como "una secta de hombres que, o por resguardar o aumentar el estado civil, afirman con desahogo que es lícita toda injusticia y afirma impíamente que se ha de tomar o dejar la religión [...] como le viniese mejor a la república o a sus particulares intentos" (apud Fernández, 1949: 425). Entonces no queda más que preguntarse cómo se puede ser político y cristiano (contrarreformado) contemporáneamente. He aquí el reto intelectual de Saavedra Fajardo.

Las Empresas políticas se pueden insertar en dos sólidas tradiciones genéricas: los tratados de educación para príncipes que ya se elaboraban desde la Edad Media, y la emblemática, cuyo primer exponente sistemático fue Alciato con su famoso Emblematum liber. Sin embargo, a diferencia de los llamados 'espejos de príncipes', el texto de Saavedra no pretende que el gobernante sea un reflejo de la doctrina ni que se mire en ella, porque para lograrlo sería necesario un modelo de comportamiento perfecto e incorruptible - entiéndase utópico. Lo que Saavedra tiene en mente es una posibilidad de príncipe circunscrita dentro de una realidad precisa: la España contrarreformista del siglo XVII.

Quizá uno de los libros que dialoga más cercanamente con las Empresas políticas sea los Emblemas morales de Sebastián de Covarrubias porque, además de la fuerte carga de elementos intertextuales - tanto en los conceptos literarios como en los visuales - la pedagogía es interés común para ambos autores. No hay que olvidar que en los Siglos de Oro la imitatio era un procedimiento creativo muy valorado y promovido. Para muchos intelectuales de la época era de suma importancia para consolidar su estatus imitar o ser imitado con fines específicos, sobre todo cuando los participantes formaban parte de la misma corte. Que se trate de un texto fundamentado en las empresas, más que una moda, es una necesidad práctica. Como bien explica Emanuele Tesauro, la empresa exige poner en relación de paridad las aspiraciones literarias, filosóficas y figurativas de una época, y sirve al espectador como un mecanismo de conocimiento de su circunstancia a partir de la configuración de estímulos disímiles. En sentido estricto, la empresa está constituida por tres elementos: una imagen (llamada también figura, pictura, etcétera), un texto (lema, mote, inscriptio, etcétera) y un comentario (glosa, epigrama, etcétera). La imagen en general es simbólica y está estrechamente relacionada con el brevísimo texto que la acompaña — en lengua extranjera, 
según las normas - y a partir de esta relación el autor elabora una explicación para anclar el sentido de la imagen a la expresión de la palabra. En el caso de Saavedra Fajardo estos comentarios, más que simples glosas, podrían considerarse auténticos textos ensayísticos, similares a los Ensayos de Montaigne (Gómez).

Las Empresas politicas tienen como objetivo hacer aflorar en el futuro gobernante las virtudes necesarias para desempeñar sus funciones. Los ejemplos que da la historia lo ayudarán a ser prudente, a no actuar sin antes haber meditado y comparado la situación presente con alguna experiencia del pasado, con miras hacia el futuro. Importante será ser precavido y tener la suficiente perspicacia para no caer en el engaño de los malos consejeros y evitar enceguecerse por las adulaciones, todo en el momento oportuno, sin caer en vicios y sin olvidar que su papel primordial es la preservación de la Razón de Estado. Mediante juegos, el pequeño príncipe practicará la justicia, la perseverancia le dará fortaleza, y el análisis de sus actos, aunado a una buena guía moral y espiritual, contribuirá a su templanza.

\begin{abstract}
Propongo a V[uestra] A[1teza] la Idea de un Príncipe Político Cristiano, representada con el buril y con la pluma para que por los ojos y por los oídos (instrumentos del saber), quede más informado del ánimo de V[uestra] A[lteza] en la ciencia de reinar, y sirvan las figuras de memoria artificiosa (Saavedra: 169).
\end{abstract}

Con estas palabras — dirigidas al príncipe Baltazar, hijo de Felipe IV— da inicio, don Diego de Saavedra Fajardo, a sus Empresas políticas. El texto tenía como objetivo criar al príncipe desde su nacimiento hasta su muerte y, para lograrlo, Saavedra recurre a imágenes y contenidos que promueven en el aprendiente modelos de conducta acordes con su función social presente y futura.

Las fuentes de la obra son muy variadas: como buen seguidor de los estudios humanísticos, Saavedra nutre su prosa con citas de pensadores de la antigüedad; como hombre interesado en la consolidación de la monarquía española, no desdeña las enseñanzas de Juan de Mariana y Alfonso X; por lo demás, siendo el libro dirigido a un príncipe cristiano, numerosas son las referencias a pasajes bíblicos que servirán para reforzar sus argumentos. Él mismo se pregunta: "¿Para qué tener por maestro a un étnico o a un impío, si se puede al Espíritu Sancto?” (175).

$\mathrm{Al}$ igual que santo Tomás, Saavedra considera que la rectitud del gobierno depende del estado de perfección del gobernante basado en la virtud, cuyo fundamento era la doctrina teológica del rey como representante de Dios en la tierra, al servicio de los gobernados. De este modo el saludable comportamiento del rey se veía reflejado en las cualidades de lo gobernado (Bajo y Betrán, 1988: 126).

Saavedra Fajardo sabía que en las empresas no podía haber elementos casuales, quizá ornamentación superflua sí, pero nunca ilustraciones de objetos en primer plano que no tuvieran una función determinante para su correcta lectura e interpretación. Consideraba también que los elementos mitológicos podían ser nocivos para la educación de los príncipes: “¿A qué lascivia no incitan las transformaciones amorosas de 
Júpiter?" (208), se pregunta, aunque no puede sustraerse del todo del conocimiento de los clásicos. En la mitología grecolatina son frecuentes las hazañas de grandes héroes en donde alcanzar los objetivos propuestos se logra gracias a la mentira, al engaño, a la traición, etcétera, conductas viciosas y repugnantes que Maquiavelo trata con toda naturalidad por tratarse de una componente humana, pero totalmente reprobables, por lo que deberían estar alejadas de cualquier gobernante que quisiera seguir siendo, además, buen cristiano. Saavedra, sin embargo, considera válido tomar ejemplos mitológicos cuando pueden tener una función alegórica efectiva y no se contraponen en ningún momento a la moral cristiana.

En la primera empresa (fig. 1) se ve, sobre un plano horizontal ajedrezado, una cuna protegida por una cortina; dentro, un niño que con sus manos parte en dos a una serpiente mientras que otra se asoma a la cuna desde el suelo con actitud amenazante. El mote sobre la filactelia dice hinc labor et virtus, o sea 'desde este momento el trabajo y la virtud'. Es obvio que Saavedra conocía la historia de la infancia de Hércules: Juno, su madrastra, lo odiaba tanto que pocos días después de haber nacido mandó dos serpientes para que lo aniquilaran. Éste fue el inicio de la tortuosa vida del héroe, quien desde niño demostró su valor y su fuerza. La historia, aunque pagana, es efectiva, pues habla del valor como una característica inmanente del hombre noble, del que será el futuro gobernante. Desde pequeño se nota la superioridad, pero poseerla no es suficiente, es necesaria una educación bien encaminada para que los valores instintivos y las virtudes innatas se perfeccionen según el hipotético modelo del príncipe cristiano óptimo, antimaquiavélico por naturaleza.

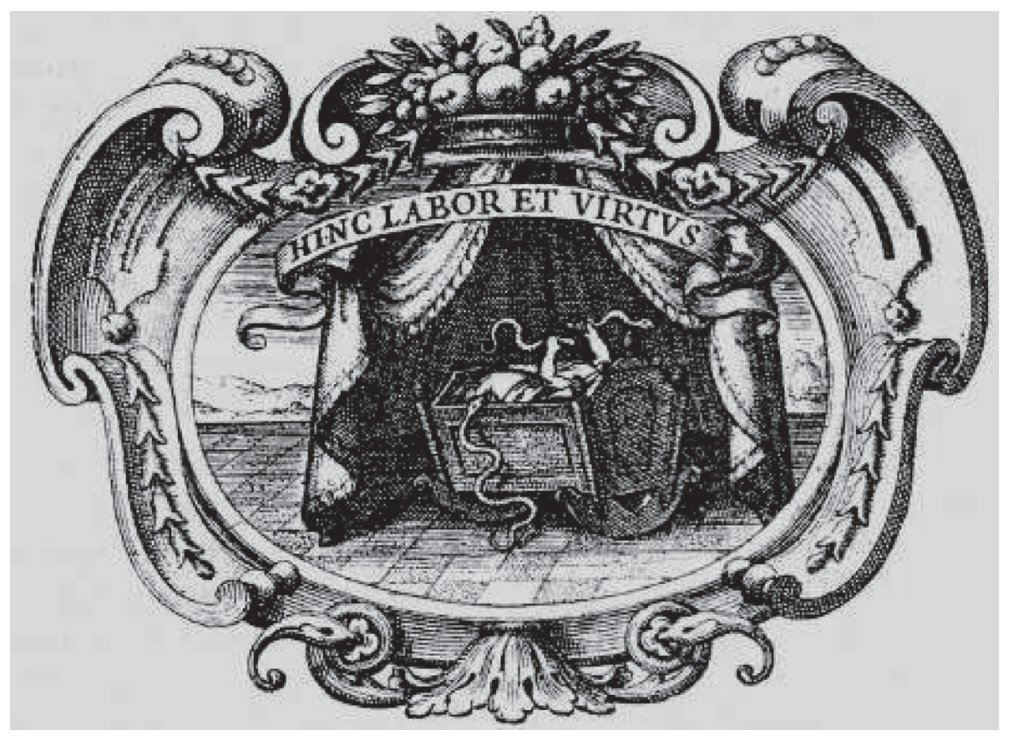

Figura 1 
Si desde la cuna se va modelando el que será gobernante, es necesario que también desde ahí se le vaya formando de la manera más adecuada para que logre ser un hombre ejemplar. El infante no tiene poder de decisión, por eso es imprescindible que se procuren todos los elementos ineludibles para tal fin. La figura femenina desempeña un papel fundamental para el desarrollo del niño, pues es el seno materno el que provee del primer alimento: Dios "puso con gran providencia en los pechos de cada una dos fuentes de cándida sangre" (Saavedra: 195). Es el primer deber de los padres procurar una buena alimentación a sus hijos, y de una madre, hacerlo con su propia leche. Sin embargo, el ambiente cortesano, la vida pública y los entretenimientos solían ser más atractivos para la nueva madre que apartarse en un lugar tranquilo para amantar al hijo, y por tal razón fueron muy apreciadas las labores de las nodrizas. Estas mujeres, cuyo servicio se pagaba y reglamentaba, eran las primeras personas con las que el niño tenía contacto. Saavedra, como muchos pensadores de la época, no estaba de acuerdo con esta práctica que, aunque reprobable y antinatural, era una realidad inevitable. Thomas Bacon, capellán del arzobispado de Crammer, opinaba al respecto, como lo reporta Saavedra:

Es deber de una madre buena y natural no entregar a sus hijos a otras mujeres, salvo en caso de verdadera necesidad, para que los alimenten, cuiden y críen con leche extraña, no amamantarlos ella misma con su propia leche. Pues ¿con qué fin ha dado Dios leche a su pecho si no es para que no esa misma leche alimente y cría a sus hijos? [...] al ser sólo medias madres, hacen una gran ofensa a Dios y corrompen la naturaleza de sus hijos [...]. Sucede así muchas veces que hijos de padres bondadosos y devotos salen groseros y malvados y completamente ajenos a la naturaleza y buena disposición de sus padres. Pues los niños, al beber una leche extraña, beben también modales extraños y una naturaleza distinta (41).

Saavedra comparte este parecer, pero es realista. Aunque la práctica sea reprobable, es una costumbre muy arraigada que, en el mejor de los casos, se debe reglamentar. El consejo del autor es el mismo de Alfonso $\mathrm{X}$ al respecto: "darles amas sanas y bien acostumbradas y de buen linaje" (195).

La segunda obligación de los padres era la crianza de los hijos, pero ésta no debía ser arbitraria. Era conveniente que las acciones instintivas del niño — todavía carente de malicia - fueran observadas y analizadas. El niño muestra con cada uno de sus gestos sus inclinaciones naturales: en este sentido "las niñeces descuidadas de los príncipes son ciertas señales y pronósticos de sus acciones adultas" (Saavedra: 195). La observación adecuada de lo impulsivo sería una excelente herramienta para la elección del mejor maestro. Saavedra se da cuenta que, aunque en ocasiones el comportamiento del niño coincide con la idea de buen cristiano, también hay casos en los que virtudes $\mathrm{y}$ vicios se concentran por igual en un mismo individuo. La acción del maestro sería entonces la de remediar los caprichos de la naturaleza, pues sólo "la razón y el arte corrigen y pulen sus obras" (200).

Revisar la historia ayuda a Saavedra a conocer la importancia de los maestros para el buen desarrollo del príncipe cristiano. Trajano o Alejandro Magno no habrían sido 
tan admirados sin sus maestros Plutarco y Aristóteles, respectivamente. Como "el maestro se copia en el discípulo, y deja en él un retrato y semejanza suya" (197), su elección debía ser rigurosamente vigilada. A este respecto, Fernández de Otero indica que "con particular cuidado y desvelo se ha de procurar hazer elección de Maestro, que no tenga inconveniente que el discípulo se le parezca en las costumbres" (apud Martínez: 1000). En los siglos XVI y XVII los interesados en la educación infantil no sólo se preocupaban por esto, sino que, además, daban consejos a los maestros para desempeñar mejor sus actividades. En el texto del emblema LXXXII de la primera centuria (fig. 2), en cuya pictura aparecen el centauro Quirón y su discípulo Aquiles, Sebastián de Covarrubias sugiere que el maestro no infunda miedo en el niño, y añade que tampoco son recomendables los castigos físicos, especialmente si el niño es noble, es más, recomienda las golosinas como incentivo:

Debe el maestro ser muy amoroso, para que el niño no le cobre miedo, y deprenda con gusto, y con reposo, sin darle un papirote con el dedo: en especial, si es noble, y generoso, no se le muestre áspero ni azedo, antes le dé la alcorza, y la rosquilla, cuando leer le mande en la cartilla.

Era bastante generalizada en la época la comparación entre la ductilidad del niño y de la cera: ambos se pueden modelar con mucha facilidad, y por eso es importante que el pequeño esté a cargo de un buen "escultor". Diego Saavedra Fajardo, en la segunda empresa (fig. 3), compara el proceso artístico con el pedagógico: el niño es susceptible de ser modificado por las formas y los colores que aplican manos ajenas sobre él, como si fuera simple materia prima. El hombre es como un lienzo en blanco, comenta, "sin idioma particular, rasas las tablas del entendimiento, de la memoria y la fantasía, para que en ellas pintase la doctrina las imágenes de las artes y las ciencias, y escribiese la educación sus documentos" (203). Las artes y las ciencias viven de forma latente al interior de cada individuo, pero sólo afloran cuando hay alguien que les brinde la instrucción adecuada: "Con la buena educación es el hombre una criatura celestial y divina, y sin ella el más feroz de todos los animales" (204), como seguramente se interpretaba la actitud del impío príncipe que describe Maquiavelo.

A pesar de la inexistencia de impedimentos para que cualquier individuo recibiera una temprana educación, no convenía que todos los niños fueran tratados por igual. El bienestar y la felicidad de un reino dependían del futuro príncipe, por eso él sí debía ser instruido con gran cuidado y atención; en cambio, si el hijo de un campesino no recibía educación alguna, a los ojos de Saavedra, no ponía en riesgo el bienestar social; además, ¿para qué querría un campesino saber latín si no lo requiere para 


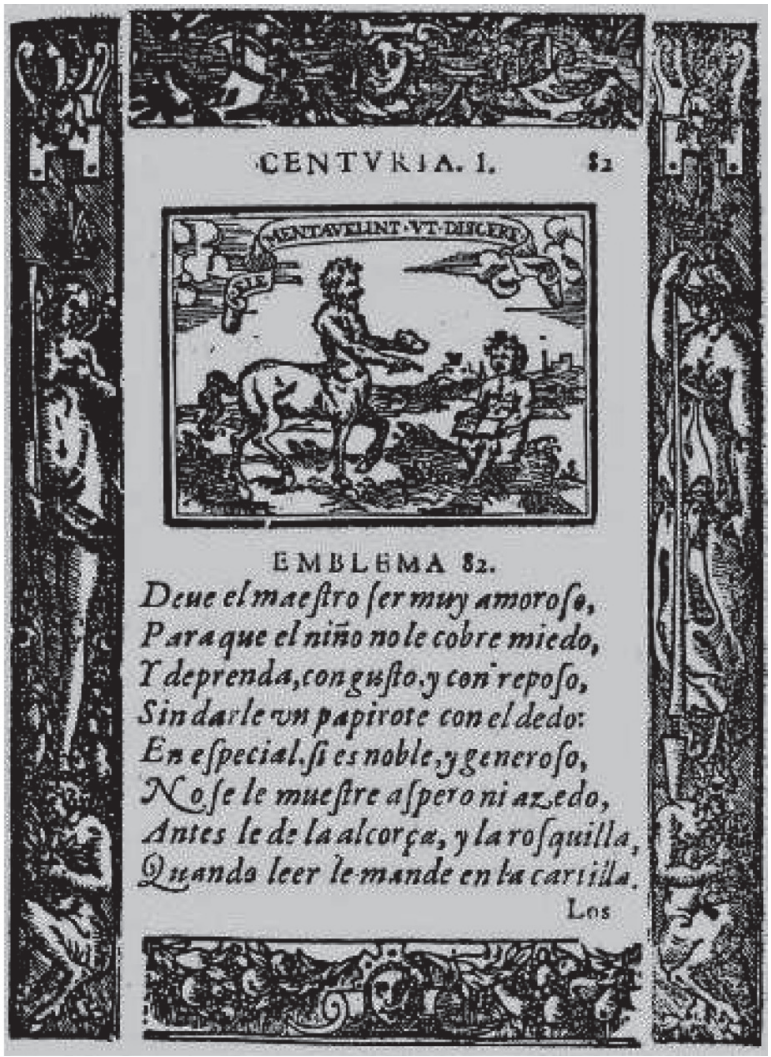

Figura 2

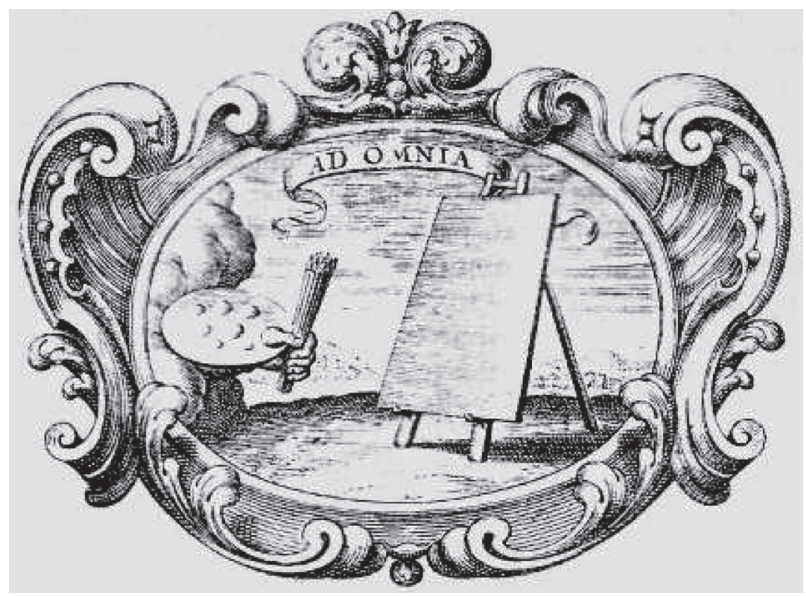

Figura 3 


\section{$24 \square$ LA PROPUESTA PEDAGÓGICA ANTIMAQUIAVELISTA DE LAS EMPRESAS POLÍTICAS}

sus actividades cotidianas? El emblema 120 de Alciato tiene como mote Paupertatem summis ingeniis obesse, ne provehantur (La pobreza impide a los grandes ingenios progresar): bajo esta afirmación — por citar un caso - se llegaron a dictar leyes para que no se enseñara gramática en las casas de expósitos. Imposible pensar que un niño pobre no tuviese problemas de aprendizaje (Delgado: 136).

Sobra decir que en España la ausencia de educación popular era un medio de control social y hasta económico, pues lo que España necesitaba en el siglo XVII era mano de obra, fuerzas bélicas y comerciantes, no intelectuales. Por lo demás, la nobleza española desdeñaba rotundamente la educación por considerarla inútil y ajena a sus actividades cotidianas. En las regiones protestantes de Europa, la actitud frente a la educación era totalmente opuesta —al menos como principio teórico-, pues ahí se consideraba que la educación era un bien necesario y útil, por lo tanto, bueno para Dios. De hecho, según Lutero, "la salud y la fuerza de una ciudad consiste en tener muchos ciudadanos instruidos, cultos, razonables, honestos y bien educados, que puedan acumular tesoros y riquezas, conservarlas y usarlas bien" (Alighiero: 308-309). Todo lo opuesto a la actitud de algunos desafortunados hidalgos españoles que debían vivir en la pobreza, pues el hecho de trabajar ponía en riesgo su título nobiliario. Mientras, en los territorios protestantes, la educación estaba legítimamente en manos de quien pudiera ofrecerla (familia, clero, instituciones laicas); como una forma de agradar a Dios, en las zonas católicas el Tribunal de la Santa Inquisición, el Index librorum prohibitorum, el Concilio de Trento y la fundación de la Compañía de Jesús constituyeron los cuatro pilares de la pedagogía. La educación católica siempre fue una forma de control social, "no como un agente inmediato de reforma, sino como un medio a largo plazo para mantener la unidad una vez conseguida ésta de nuevo" (Bowen: 52). Para ejercer este control de manera lícita, Pablo III reorganizó el Tribunal de la Inquisición en 1542 y en 1557 se promulgó el Index. En 1571, Pio V instauró la Sacra Congregación del Índice con el afán de tener control sobre los materiales impresos; además, promovió la elaboración de catálogos actualizados de los libros ya prohibidos. Todas las obras de Maquiavelo entraron en el Índice. Evidentemente los intelectuales españoles de la época no podían sustraerse de la política internacional, por eso es que la obra de Maquiavelo fue ampliamente comentada durante los siglos XVI y XVII. Las posibilidades para tener acceso a estos textos prohibidos en territorio católico fueron dos: o se conocían mediante citas y comentarios de segunda mano o, en realidad, se tenía resguardado algún ejemplar parcial o total, impreso o manuscrito, a partir del cual nacieron ulteriores reflexiones. Sólo así se explica que Maquiavelo sea citado con tanta precisión tanto en lengua toscana como en traducción castellana. Para la mentalidad de la Contrarreforma, era necesario evitar las herejías — entendidas como cualquier tipo de desviación de la única y verdadera doctrina religiosa o política. En este afán y para reforzar dicha ideología, la Inquisición era incluso condescendiente con los que denigraban lo ya prohibido con conocimiento de causa. ¿Cómo es que los tratadistas políticos cristianos se podían enfrentar con rigor y coherencia al pensamiento de Maquiavelo si no tenían acceso a sus libros? Tener acceso a un texto, sin embargo, no implica su efectiva comprensión. 
Diego Saavedra Fajardo había desempeñado actividades diplomáticas de 1633 a 1643 en las regiones de Baviera y Borgoña, así como en las ciudades de Ratisbona, Viena y Milán, por lo que es posible suponer que conoció la importancia que se le prestaba a la educación en las cortes que lo acogieron. Para el autor, "el arte de reinar no es don de la naturaleza, sino de la especulación y de la experiencia. Sciencia es de las sciencias" (234). Importante es la unión del pensamiento con la acción: Saavedra no confiaba en los arbitristas porque sus propuestas eran fruto de un razonamiento esmerado - acaso legítimo y válido-, pero no de la práctica o la observación de hechos concretos. No hay que olvidar que un gran número de tratadistas políticos pertenecían al clero, y que no todos ejercieron algún tipo de actividad política significativa.

En ninguna de las empresas se hacen críticas a la Iglesia romana, pero sí a sus adeptos, especialmente cuando las acciones de éstos pudieran poner en riesgo la buena educación del príncipe. Si bien la buena elección de maestros es fundamental, el entorno también tiene un papel determinante para el óptimo desarrollo físico y mental del futuro gobernante: "No solamente conviene reformar el palacio en las figuras vivas, sino también en las muertas, que son las estatuas y pinturas: porque, si bien el buril y el pincel son lenguas mudas, persuaden tanto como las más fecundas" (208); por tal motivo, en las Empresas políticas se recomienda con insistencia que la decoración palaciega fomente en el niño la emulación de los hechos y los valores representados en pinturas y esculturas. Además de la adecuada nutrición y la elección de un maestro competente, el entorno físico cumple una función pedagógica de alto relieve, pues el príncipe aprende de lo que ve, por lo que una educación inclinada hacia los placeres podría ser altamente contraproducente. Dentro del programa educativo de los pequeños nobles no sólo se tomaba en cuenta el ser, sino el parecer, por eso para Saavedra Fajardo no basta con parecer virtuoso, hay que serlo de veras, sin caer en la disimulación deshonesta de los vicios y la simulación de las virtudes para causar daño, como describe Maquiavelo, sino usarlos como métodos de protección cuando fuera pertinente. No es suficiente seguir el consejo de Alfonso X y tener hijos con una mujer hermosa para que éstos nazcan con características físicas similares: el cuerpo del príncipe debe embellecerse con la calidad del alma, no al revés. "El vulgo juzga por la presencia las acciones, y piensa que es mejor príncipe el más hermoso", comenta Saavedra, y en seguida se cuestiona: “¿Qué importa que el príncipe sea dispuesto y hermoso, si solamente satisface a los ojos, y no al gobierno?" (217). Aunque era una idea muy arraigada pensar que la apariencia externa era reflejo de la virtud interior, Saavedra apunta que, en ocasiones, la naturaleza descuida éstas por trabajar en aquélla. En este sentido, una de sus preocupaciones es que el príncipe se preocupe más por su aspecto que por la virtud. El deleite es bueno, pero la verdadera función del gobernante es defender, pelear, ocuparse de política y no de afeites, y por eso aconseja que el príncipe también se críe fuera del palacio, que haga ejercicios físicos — practicar la caza, por ejemplo-, pues si los futuros gobernantes "se crían entre los armiños y las delicias, que ni los 


\section{$26 \square$ LA PROPUESTA PEDAGÓGICA ANTIMAQUIAVELISTA DE LAS EMPRESAS POLÍTICAS}

visite el sol ni el viento ni sientan otra aura que la de los perfumes, salen achacosos e inútiles para el gobierno, como al contrario, robusto y hábil quien se entrega a las fatigas y a los trabajos" (Saavedra: 213). La virtud, por lo tanto, llega con el estudio y el esfuerzo, no viene incluida en el apellido ni se obtiene con dinero. La importancia del aspecto del niño se acrecentó con los Habsburgo, como muestran muchos retratos realizados bajo su auspicio. Con ellos surgió la moda de vestir a los niños como pequeños adultos a partir de los cuatro o cinco años; antes de esa edad, solía envolvérseles con complicadas fajas para corregir posibles deformidades (Bajo y Betrán: 49). El niño tenía que verse a sí mismo y mostrarse ante los demás como príncipe para no olvidar su futura función social.

En el mote de la quinta empresa se lee "Deleitando enseña" (fig. 4). La pictura es la vista de una fortaleza desde lo alto, aunque en realidad se trata de un jardín barroco, laberíntico, que alude a la forma de la fortificación, en cuyo centro se encuentra una esfera armilar. Lo que la empresa indica es que la realidad — a veces cruel— se debe disfrazar agradablemente para que el príncipe la conozca poco a poco antes de enfrentársele. El juego se vuelve la vida del niño; un buen recurso para que adquiera conocimientos y experiencias que le servirán para su vida futura. En el caso de los príncipes, todo juego debería estar enfocado a sus actividades militares y de gobierno. No es nocivo que el aprendizaje sea divertido, al contrario: con el juego el niño aprende y en este sentido conviene que los juegos propuestos por los maestros estén pedagógicamente diseñados para el provecho futuro del aprendiente. La letra no entra con sangre sino con reglas simples, claridad y ejercitación disfrazada de juego (Bajo y Betrán: 90). De hecho, las actividades lúdicas permiten descubrir las aptitudes y deficiencias del niño. Saavedra recomienda:

Recítenle panegíricos de sus agüelos, que le exhorten y animen a la emulación, y él también los recite, y haga con sus meninos otras representaciones de sus gloriosas hazañas, en que se inflame el ánimo; porque la eficacia de la acción se imprime en él, y se da a entender que es el mismo que representa. Remede con ellos los actos del rey, fingiendo que da audiencias, que ordena, castiga y premia; que gobierna escuadrones, expugna ciudades y da batallas (209-210).

Para aprender a leer, Saavedra aconseja usar un juego de fichas que representen cada letra del alfabeto y una placa con letras grabadas en relieve para facilitar el deslizamiento de la pluma sobre ellas. La mejor forma que hay para que el niño aprenda diferentes lenguas es poner a sus disposición acompañantes de varios puntos del planeta, de tal suerte que, como la lengua materna, aprenda cualquier otra de manera natural, prescindiendo de los obsoletos métodos tradicionales. La geografía y la astronomía se pueden aprender fácilmente si las paredes de sus habitaciones están decoradas con detallados tapices que muestren mapas terrestres y celestes. Para ejercitar el conocimiento geométrico hay que jugar a medir los objetos que lo rodean, así como construir campos de batalla en escala. Además, réplicas de soldados de metal ayudarán 


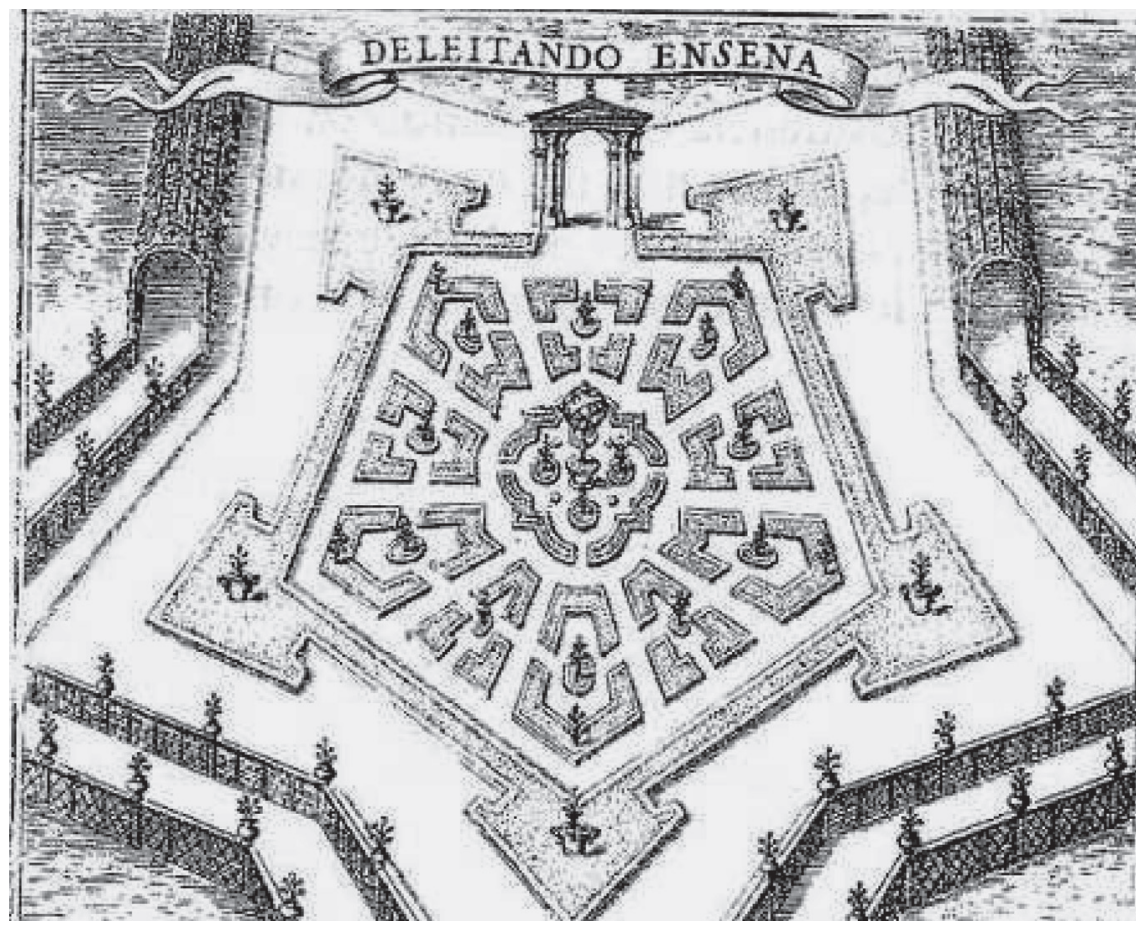

Figura 4

a simular batallas. Para consolidar este propósito, Saavedra comenta que "no ha de tener el príncipe en la juventud entretenimiento ni juego que no sea una imitación de lo que después ha de obrar de veras" (233). Aunque en todo momento Saavedra le recuerda al príncipe que, en última instancia, es la Divina Providencia quien se encarga de otorgar victorias o derrotas, por lo tanto, tener la mirada fija en Dios genera éxito: "Lo primero que ha de enseñar el maestro al príncipe es el temor de Dios, porque es principio de la sabiduría. Quien está en Dios, está en la fuente de las sciencias. Lo que parece saber humano es ignorancia, hija de la malicia, por quien se pierden los príncipes y los Estados" (227). Evidentemente, el conocimiento de las obras de Maquiavelo por parte del príncipe no estaba contemplada como sustento teórico para la instrucción futura, pero sí la capacidad para distinguir entre lo que es bueno para la conservación de la Razón de Estado y lo que es perjudicial para la moral cristiana. Sin embargo, Saavedra afirma que "con el hombre nació la razón de Estado, y morirá con él sin haberse entendido perfectamente" (234), es decir, el quehacer político no es una parte inherente de la religión, sino de las actividades humanas, y es tan complejo en su esencia que ni siquiera el ser humano es competente para entenderlo. Siendo así, las Empresas políticas son un intento por explicar qué es la Razón de Estado y cómo se puede llegar a ella a partir de una educación esmerada y 
cuidadosa donde es posible que haya un delicado connubio entre la corruptible naturaleza humana y la perfección de la religión.

\section{Obras citadas}

ALDEA, Quintín. Ed. 1986. España y Europa en el siglo XVII: correspondencia de Saavedra Fajardo. Madrid: Consejo Superior de Investigaciones Científicas, Centro de Estudios Históricos, Departamento Enrique Flórez.

Alighiero, Mario. 1992. Historia de la educación: del 1500 a nuestros días. Trad. Miguel MARTí. México: Siglo XXI.

BAjo, Fe y José Luis BetráN. 1988. Breve historia de la infancia. Madrid: Temas de Hoy.

Botero, Giovanni. 1589. Della Ragione di Stato. Venecia: Giolitti.

Bowen, James. 1992. Historia de la educación occidental: el occidente moderno. Barcelona: Herder.

Covarrubias, Sebastián de. 1610. Emblemas morales. Madrid: Luis Sánchez.

Delgado, Buenaventura. 2000. Historia de la infancia. Barcelona: Ariel.

FERNÁNDEZ, Gonzalo. 1949. "Maquiavelo visto por los tratadistas políticos españoles de la Contrarreforma". Arbor, núm. XIII. Madrid: Arbor Revistas. Pp. 416-449.

FERNÁNDEZ, José A. 1986. Razón de Estado y política en el pensamiento español del barroco (1595-1640). Madrid: Centro de Estudios Constitucionales.

GómEZ, José Luis. 1979. "Reflexiones ante las Empresas de Saavedra Fajardo". Nueva Revista de Filología Hispánica, núm. 28. México: El Colegio de México. Pp. 374-384.

MARTínEZ, Ana. 2000. "Educación y primeras letras en los Emblemas morales de Sebastián de Covarrubias". Del Libro de Emblemas a la Ciudad Simbólica: Actas de 3er. Simposio Internacional de Emblemática Hispánica, vol. II. Castelló de la Palma: Universitat Jaume I. Pp. 979-1007.

MENDO, Andrés. 1662. Príncipe perfecto y ministros ajustados. Documentos politicos y morales en emblemas. León de Francia: Horacio Boissat y George Remeus.

RIVADENEIRA, Pedro de. 1595. Tratado de la religión y virtudes que deve tener el Príncipe Christiano para governar y conservar sus Estados. Contra lo que Nicolás de Maquiavelo y los Políticos deste tiempo enseñan. Madrid: [s. e.]. SAAVEDRA, Diego. 1999. Empresas políticas. Ed. Sagrario LóPEZ PozA. Madrid: Cátedra. 